\title{
Measurements and parameterizations of small aerosol deposition velocities to grassland, arable crops, and forest: Influence of surface roughness length on deposition
}

\author{
M. W. Gallagher, ${ }^{1}$ E. Nemitz, ${ }^{2}$ J. R. Dorsey, ${ }^{1}$ D. Fowler, ${ }^{2}$ M. A. Sutton, ${ }^{2}$ \\ M. Flynn, ${ }^{1}$ and J. Duyzer ${ }^{3}$ \\ Received 7 May 2001; revised 26 June 2001; accepted 24 August 2001; published 26 June 2002.
}

[1] New micrometeorological measurements of small (0.1-0.2 $\mu \mathrm{m}$ diameter) aerosol particle fluxes using the eddy correlation technique are presented for moorland and also for grassland vegetation, the latter measurements being made both before and after cutting of the grassland to observe the resultant change in particle deposition velocity. These data are considered together with previously reported and reanalyzed micrometeorological measurements, again using the eddy correlation technique, for a number of different surface types, including arable crops and forest. Differences in observed surface deposition velocities, $v_{d s}$, due to the different surface roughnesses are highlighted. It was found that the various data sets showed a wholly consistent behavior when ensemble averages over the typical range of atmospheric stability ranges are considered in order to reduce the scatter inherent in these types of measurements. A working parameterization of surface deposition velocity in terms of the surface's roughness length, $z_{o}$, is presented. This is then extended for different atmospheric stabilities, using the parameterization suggested by Lamaud et al. [1994c], to yield $v_{d s} / u_{*}=k_{1}+k_{2}(-300 z / L)^{2 / 3}$, where $k_{1}=k_{1}=$ $0.001222 \log \left(z_{o}\right)+0.003906, k_{2}=0.0009$, where $z$ is the measurement height, $L$ is the Obukhov stability length, and $u *$ is the local friction speed. The new data are finally compared to current analytical model descriptions of the deposition process, highlighting deficiencies in our understanding of the surface collection efficiency even for these small particles. INDEX TERMS: 0305 Atmospheric Composition and Structure: Aerosols and particles (0345, 4801); 0315 Atmospheric Composition and Structure: Biosphere/atmosphere interactions; KEYWORDS: aerosol, dry deposition, eddy correlation, surface resistance, roughness length, vegetated surface

\section{Introduction}

[2] The process of dry deposition has consumed considerable resources over many decades in an attempt to estimate quantitatively the removal rate of atmospheric aerosols to or from terrestrial surfaces. Although the many different turbulent, chemical, and even electrical mechanisms that can contribute to the process of deposition or emission have been discussed extensively in the literature over the years, our knowledge remains incomplete. Progress has essentially been limited to bulk estimates of the speciated dry deposition flux. This has been mainly due to the complex interdependence of many different variables that can control the exchange process of atmospheric condensates to surfaces that are complex both at the microscale in terms of morphology and at the terrain scale. Although there

\footnotetext{
${ }^{1}$ Physics Department, University of Manchester Institute of Science and Technology, Manchester, UK.

${ }^{2}$ Centre for Ecology Hydrology, Penicuik, UK.

${ }^{3}$ TNO, Apeldoorn, Netherlands.
}

Copyright 2002 by the American Geophysical Union. 0148-0227/02/2001JD000817 have been many models that seek to explain the deposition process to complex surfaces by taking into account variables such as particle size, composition, surface morphology, meteorology, and turbulence, their predictions vary widely [Ruijgrok et al., 1995]. Although many of these models were primarily designed for single surface types, attempts have been made to extend their predictions to other surfaces. This is despite the fact that most of these models rely on parameterizations obtained by wind tunnel studies, which were mainly based on measurements using simulated or short vegetated surfaces [Chamberlain, 1966; Nicholson, 1988]. It is often stated that such studies, although providing valuable insights into exchange processes, are not fully representative of atmospheric surface layer turbulent exchange processes; in particular, of the influence of atmospheric stability.

[3] The review by Ruijgrok et al. [1995] of the performance of several models, when compared with deposition data inferred mostly from throughfall measurements, suggested that one of the largest areas of uncertainty occurred for a particular size range, the crucial accumulation mode, 0.1$1.0 \mu \mathrm{m}$. Whereas most models, again using mainly wind tunnel derived parameterizations, predict very low deposition velocities, $\approx 0.1 \mathrm{~mm} \mathrm{~s}^{-1}$, many field studies suggested 
values of 1 order of magnitude or larger. Owing to technical limitations, most experimental studies have employed a variety of techniques, ranging from indirect to direct micrometeorological, both for aerosol tracer species such as sulphate and for size-segregated particle size distribution measurements. There is now a growing database of micrometeorological and related measurements for aerosol deposition [e.g., Wesely et al., 1977, 1985; Everett et al., 1979; Sievering, 1982, 1983, 1987, 1988; Hicks, 1984, 1987; Duyzer and Bosveld, 1988; Beswick et al., 1994; Duyzer et al., 1994; Lamaud et al., 1994a, 1994b; Fontan et al., 1997; Hummelshoj, 1992; Joutsenoja, 1992; Wyers et al., 1994; Wyers and Duyzer, 1997].

[4] Although the review by Gallagher et al. [1997a] demonstrated a consistent trend in many field measurements of deposition velocity across the aerosol size spectrum, despite the wide variety of techniques used, our knowledge is still incomplete. Progress is also hampered by the lack of a consistent methodological approach for interpreting measurements from very different techniques. The influence of sampling artifacts, statistical limitations, bidirectional flux interpretation, and low-frequency spectral contributions have still not been addressed in a coherent manner. The influence of relative humidity on particle equilibrium size as a function of dry particle size and composition may also cause sizing artifacts with various techniques. Furthermore, the influence of deliquescence effects on eddy correlation fluxes has received scant attention. A. Kowalski (personal communication, 2000) has suggested that the errors induced in deposition velocity may be large, causing either an underestimate in deposition velocity, e.g., under warm humid conditions, or an apparent upward flux with errors potentially as large as the deposition velocity, whereas Buzorius et al. [2000] suggest that the maximum error is a few tens of percent under unfavorable conditions. At present these errors are have not been considered in a quantitative manner by the surfaceatmosphere exchange community, and this problem will remain for some time until sufficiently detailed and unambiguous measurements of dry deposition rates can be made. For now the work consists of increasing the current database using micrometeorological techniques to a variety of natural vegetated surfaces capable of being used to test current models of the deposition process in greater detail.

[5] In this paper therefore we report recent measurements of aerosol deposition velocity made over grassland and heathland as part of the National Environment Research Council Environmental Diagnostics Programme and compare them with previous measurements for agricultural crops and forest. In this paper it is the aim primarily to highlight the differences caused by surface morphology and to concentrate solely on small particle deposition. The influences of other variables such as atmospheric stability and, in particular, the particle size dependency on collection efficiency will be discussed in a subsequent paper. The measurements will then be compared briefly with predictions using current analytical models to highlight shortcomings in our understanding of the various surface-particle interaction processes.

\section{Methodology}

[6] Micrometeorological eddy correlation techniques for estimating aerosol dry deposition were initiated by Wesely et al. [1977] and Sievering [1982], and the analytical approach as well as the instrumentation [Sievering, 1989] used have changed little since. The generally accepted approach for determining the flux, $F$, of aerosol by micrometeorological techniques for surface exchange is to employ eddy correlation. In the case of a size-segregated particle flux, $F\left(d_{p}\right)$ is found from

$$
F\left(d_{p}\right)=\overline{w^{\prime} \chi^{\prime}\left(d_{p}\right)}
$$

where $w^{\prime}$ is the vertical velocity perturbation and $\chi^{\prime}\left(d_{p}\right)$ is the perturbation in concentration of the aerosol concentration with diameter $d_{p}$. The total aerosol mass flux is then determined by integration over the particle size spectrum, assuming a composition or mass-size distribution is available. The overbar represents an average, typically 30 min in the surface layer, against which the velocity and concentration perturbations are measured. The deposition velocity is then defined as

$$
v_{d}=-\overline{w^{\prime}\left(\frac{\chi^{\prime}}{\chi}\right)},
$$

where the minus sign is used to define deposition by convention as being positive toward a surface, whereas vertical velocity is defined as being positive upward. This equation is equivalent to

$$
v_{d}=-\frac{\overline{w^{\prime} \chi^{\prime}}}{\bar{\chi}}
$$

when fluctuations are significantly smaller than the concentration.

[7] A general discussion of eddy correlation instrumentation and analytical techniques for size-segregated aerosol is discussed by Sievering [1982, 1983, 1987] and Beswick et al. [1994] and, for total aerosol fluxes, by Katen and Hubbe [1983], Fontan et al. [1997], and Buzorius et al. [1998, 2000]. We will not discuss these details in this short paper. Particle concentrations are normally measured by optical particle counters that rely on scattered laser radiation whose intensity is related to the size of the particle as defined by Mie theory. The key parameters determining the error associated with a particle number flux measured by eddy correlation optical particle counters are the sample volume of the particular instrument, the ambient particle size distribution, the mean wind speed, surface layer stability, and the measurement height. The limitations of single particle counting instruments for atmospheric measurements are numerous and are discussed in detail by the above-mentioned references and by Fairall [1984].

[8] The resistance analogy for atmospheric transport of a scalar contaminant to surfaces in the turbulent surface layer is usually used to separate the turbulent transport and surface interaction so that the "dry" deposition velocity, $v_{d}$, is expressed in the form

$$
v_{d}=v_{g}+\frac{1}{\left(r_{a}+r_{s}\right)},
$$


where $v_{g}$ is the sedimentation velocity due to gravity, $r_{a}$ is the aerodynamic resistance due to turbulent transport to the surface, and $r_{s}$ is the surface resistance to uptake and is expected to be a strong function of size and stability. The value $v_{g}$ is provided by the Stokes equation:

$$
v_{g}=\frac{\rho d_{p}^{2} g C}{18 \eta}
$$

where $\rho$ is the particle density, $d_{p}$ is its "dry" diameter, $g$ is the acceleration due to gravity, $\eta$ is the viscosity coefficient for air, a function of pressure and temperature, and $C$ is the Cunningham slip-flow correction for small particles given by

$$
C=1+\frac{2 \lambda}{d_{p}}\left(1.257+0.4 e^{-0.55 \frac{d_{p}}{\lambda}}\right)
$$

[e.g., Pruppacher and Klett, 1980], where $\lambda$ is the mean molecular free path for air, which is again a function of pressure and temperature.

[9] The aerodynamic resistance to transfer to the top of the laminar sublayer, $r_{a}$, of the collecting surface is obtained from

$$
r_{a}=\frac{\ln \left(\frac{z_{\mathrm{ref}}-d}{z_{0}}\right)-\psi_{H}}{\kappa u_{*}},
$$

where $z_{\text {ref }}$ is the reference height at which $v_{d}$ is calculated, $z_{o}$ is the roughness length, a function of canopy height and wind speed depending on canopy type, $\kappa$ is von Kaman's constant $(\approx 0.4), u_{*}$ is the local friction speed that can be obtained from measurement of the local momentum flux through, $u_{*}^{2}=-\overline{u^{\prime} w^{\prime}}$ and $\psi_{H}$ is the dimensionless stability function for heat [Paulson, 1970]. The surface capture efficiency can then be represented by the "surface" deposition velocity $v_{d s}$,

$$
v_{d s}=\frac{1}{r_{s}}
$$

which can then be related to surface morphology. Note that the measured deposition velocity using the eddy correlation technique excludes the sedimentation component and is related directly to the resistance terms

$$
v_{d}=\frac{1}{\left(r_{a}+r_{s}\right)} .
$$

This can then be related to surface morphology descriptors. The surface term $r_{s}$ can be further divided into additional resistance terms

$$
r_{s}=r_{b}+r_{c}
$$

where $r_{b}$ is the resistance to transfer of particles across the laminar boundary layer and may include the effect of many different types of processes, and $r_{c}$ is the canopy resistance to deposition, which is essentially what is measured by difference with $r_{b}$ calculated based on theoretical descriptions. There are many formulations for $r_{b}$, some of which include descriptions of the leaf area index (LAI); however, a commonly used, although simplistic, approach is

$$
r_{b}=\frac{\ln \left(z_{0} / z_{0 c}\right)}{k u_{*}},
$$

where a secondary sink height, $z_{o c}$, the contaminant sink height is defined for particles.

\section{Measurement Data Sets}

[10] Aerosol deposition velocity data for five different surface types are presented and contrasted. The measurements were obtained at (1) a heathland site (Auchencorth Moss) in southern Scotland, and the experimental site and the results are discussed in detail by Flechard and Fowler [1998] and Nemitz et al. [2002]; (2) a managed grassland experiment conducted under the GRAMINAE programme at Braunschweig, Germany [Sutton et al., 2001], where two sets of measurements were obtained, the first over long grass and the second over the same fetch after the grass was harvested; two final data sets, one over (3) an arable crop site composed of winter barley and previously published by Gallagher et al. [1997a] and (4) the other described by Joutsenoja [1992], again in southern Scotland; and (5) the final data set for a dense Douglas fir forest canopy in the Netherlands, published and described by Beswick et al. [1994]. Hereafter the different experiments will be referred to by their surface types, i.e. as heathland, short and long grass, arable crop, and forest. Micrometeorological parameters and canopy variables pertaining to the various surfaces are summarized in Table 1 . Table 1 also contains a summary of previous micrometeorological field experiments and particle deposition parameterizations that will be referred to later. The key parameter under investigation here is the surface roughness length, $z_{o}$. In all cases except the arable crop experiment this variable was determined by a combination of long-term wind profile and single-eight eddy correlation measurements of momentum flux and are referred to in the above references. In the arable crop case the roughness length was estimated from measured drag coefficients and literature values for similar surfaces.

[11] At present there is general uncertainty as to how upward fluxes and size-dependant bidirectional fluxes that are sometimes observed can be interpreted. When these processes occur, significant differences in deposition velocity magnitudes can be inferred on the basis of data-handling protocols. The data presented here will adopt the following analysis methodology: For heathland the results are as presented by Nemitz et al. [2002] and are the average of all flux measurements; for the short- and long-grass experiments the flux measurements used were averages for all fluxes, which included some emission periods; for the arable crop, surface data are also presented as net deposition values, although in this case, Joutsenoja [1992] did not report any contribution from apparent upward fluxes, and hence we assume that the fluxes values represent contributions from both deposition and possible emission processes for the aforementioned canopies; and the forest data are also presented as net deposition velocities except for one short period where very strong size-dependant bidirectional 
Table 1. Summary of Aerosol Dry Deposition Experiments and Parameterizations Obtained by Micrometeorological Techniques ${ }^{\mathrm{a}}$

\begin{tabular}{|c|c|c|c|c|}
\hline Experiment & Description & Stability & Reference & Parameterization \\
\hline Elspeet & $\begin{array}{l}\text { heathland, Netherlands; } \\
\text { roughness length } z_{o}=0.032 \mathrm{~m} ; \\
\text { zero plane displacement } \\
\text { height } d=0.3 \mathrm{~m}\end{array}$ & $L \leq 0^{\mathrm{b}}$ & Nemitz et al. [2002] & $\begin{array}{c}v_{d s} / u_{*}=A\left(1+(B / L)^{2 / 3}\right) ; d_{p}=87.867 ; \\
A=0.001 ; B=960.33^{\mathrm{c}}\end{array}$ \\
\hline Speulderbos & $\begin{array}{l}\text { forest, Netherlands; Douglas Fir } \\
\quad h=18-20 \mathrm{~m} ; d=11 \mathrm{~m} ; \\
z_{o}=2.5 \mathrm{~m} ; \mathrm{LAI}^{\mathrm{d}}=10-17\end{array}$ & $L>0^{\mathrm{e}}$ & Beswick et al. [1994] & $v_{d s} / \mathrm{u} *=0.003-0.004 ; d_{p}=0.4$ \\
\hline Speulderbos & & $L \leq 0$ & & $v_{d s} / u_{*}=0.0135 ; d_{p}=\left[1+(-300 / L)^{2 / 3}\right]$ \\
\hline $\begin{array}{l}\text { DDIE }^{\mathrm{f}} \\
\mathrm{ANL}^{\mathrm{f}}\end{array}$ & $\begin{array}{l}\text { lush grass } \\
\text { pine forest } \\
\text { leafless deciduous } \\
\text { grazed pasture }\end{array}$ & $\begin{array}{l}L>0 \\
L \leq 0 \\
L \leq 0 \\
L \leq 0\end{array}$ & $\begin{array}{l}\text { Wesely et al. }[1985] \\
\text { Hicks et al. }[1987] \\
\text { Wesely et al. }[1983 \mathrm{a}] \\
\text { Wesely et al. }[1983 \mathrm{~b}]\end{array}$ & $\begin{array}{c}v_{d s} / u_{*}=.002 \\
v_{d s} / u_{*}=0.002\left[1+(-300 / L)^{2 / 3}\right] \\
v_{d s} / u_{*}=0.002\left[1+(-300 / L)^{2 / 3}\right] \\
v_{d s} / u_{*}=0.002\left[1+\left(-0.3 z_{i} / L\right)^{2 / 3}\right]^{\mathrm{g}}\end{array}$ \\
\hline Landes & $\begin{array}{l}\text { Landes Forest; Pinus Pinaster } \\
\text { Aif } h=15 \mathrm{~m} ; \mathrm{LAI}=3 ; d=11 \mathrm{~m} ; \\
z_{o}=1.4 \mathrm{~m}\end{array}$ & $L>0$ & $\begin{array}{l}\text { Lamaud et al. }[1994 \mathrm{a}, \\
\text { 1994b, 1994c] }\end{array}$ & $v_{d s} / u_{*}=k_{1} ; k_{1}=0.004$ \\
\hline Stars I & $\begin{array}{l}\text { Sahel Niger, Africa; bare clay } \\
\text { soil; } z_{o}=0.002 \mathrm{~m}\end{array}$ & $L>0$ & $\begin{array}{l}\text { Lamaud et al. }[1994 \mathrm{a}, \\
\quad 1994 \mathrm{~b}, 1994 \mathrm{c}]\end{array}$ & $v_{d s} / u_{*}=k_{1} ; k_{1}=0.002$ \\
\hline \multirow[t]{2}{*}{ Stars II } & $\begin{array}{c}\text { Ebre Valley; bare soil, sparse } \\
\text { almond trees; } z_{o}=0.0025- \\
0.01-0.1 \mathrm{~m}\end{array}$ & $L>0$ & $\begin{array}{l}\text { Lamaud et al. }[1994 \mathrm{a}, \\
\text { 1994b, 1994c] }\end{array}$ & $v_{d s} / u_{*}=k_{1} ; k_{1}=0.002$ \\
\hline & all surfaces & $L \leq 0$ & Lamaud et al. [1994c] & $\begin{array}{c}v_{d s} / u *=k_{1}+k_{2}\left(-z_{i} / L\right)^{2 / 3} \\
k_{2}=0.0009\end{array}$ \\
\hline Howmuir & $\begin{array}{l}\text { winter barley; } u_{*}=0.68 \mathrm{~m} \mathrm{~s}^{-1} \\
\quad h=1.2 ; z_{o}=0.08-0.12\end{array}$ & $L \leq 0$ & Joutsenoja [1992] & $v_{d}=0.045-0.0371 d_{p}+4.26 * d_{p}^{2 \mathrm{~h}}$ \\
\hline Auchencorth & $\begin{array}{c}\text { heathland; } u_{*}=0.32 \mathrm{~ms}^{-1} \\
z_{o}=0.01 \mathrm{~m} \text {; canopy } \\
\text { height }=0.06 \mathrm{~m} \text {; zero plane } \\
\text { displacement } d=0.04 \mathrm{~m} .\end{array}$ & neutral & Nemitz et al. [2002] & see text \\
\hline GRAMINAE & $\begin{array}{c}\text { managed grassland, long grass; } \\
u_{*}=0.24 \mathrm{~ms}^{-1} ; u=2.29 \mathrm{~ms}^{-1} \\
\text { canopy height } h=0.60-0.75 \mathrm{~m} \\
z_{\text {measure }}=2.86 \mathrm{~m}\end{array}$ & neutral & $\begin{array}{l}\text { this work; } \\
\text { Sutton et al. }[2001] ; \\
\text { Dorsey et al. }[2002]\end{array}$ & see text \\
\hline GRAMINAE & $\begin{array}{l}\text { short grass; } u *=0.18 \mathrm{~ms}^{-1} \\
u=2.19 \mathrm{~ms}^{-1} ; \text { canopy height } \\
h=0.14 \mathrm{~m} ; z_{\text {measure }}=2.86 \mathrm{~m}\end{array}$ & neutral & $\begin{array}{l}\text { this work; } \\
\text { Sutton et al. [2001]; } \\
\text { Dorsey et al. }[2002]\end{array}$ & see text \\
\hline Summary & all surfaces & & $\begin{array}{l}\text { this work; } \\
\text { Nemitz et al. }[2002]\end{array}$ & $\begin{array}{c}v_{d s} / u_{*}=k_{1}+k_{2}(-300 z / \mathrm{L})^{2 / 3} \\
k_{1}=0.001222 * \log \left(z_{o}\right)+0.003906 \\
k_{2}=0.0009\end{array}$ \\
\hline
\end{tabular}

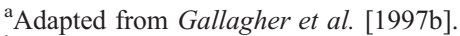

${ }^{\mathrm{b}}$ Indicates that value is unstable.

${ }^{\mathrm{c}}$ Aerosol diameter $d_{p}$ is measured in $\mu \mathrm{m}$ with range $0.1-0.5 \mu \mathrm{m}$.

${ }^{\mathrm{d}}$ LAI denotes leaf area index.

e Indicates that value is stable.

${ }^{\mathrm{f}} \mathrm{DDIE}$ and AAL are experimental numbers defined in corresponding references.

${ }^{\mathrm{g}}$ Value $z_{i}$ is boundary layer depth.

${ }^{\mathrm{h}}$ Value of $v_{d}$ is measured in $\mathrm{cm} \mathrm{s}^{-1}$
}

fluxes were observed, particularly for small particles [Beswick et al., 1994], and were rejected from the analysis. Thus there may be some inconsistency when intercomparing the different data sets, but as we shall see, this apparently does not affect the general behavior observed, as noted by Nemitz et al. [2002]. In all of the subsequent data sets the deposition velocities are based on ensemble averages of 15- or 20-min measured fluxes for the chosen size range $0.1-0.2 \mu \mathrm{m}$ diameter. The number of measurements for each data set varied from 200 (for the agricultural crop) to $>1000$ for the grassland surfaces. Apart from the measurements made over the forest surface the mean atmospheric stability encountered for all the surfaces for which the measurements were valid (note these are for northern European sites) was typically close to neutral with and $|z / L|<0.05$. Thus the resulting deposition values shown in section 4 do include some stability influences, but the contribution of large instability effects are small due to the small number, although this is not the case for the forest database, which exhibits significantly larger standard deviations than the other databases. Although this ensembleaveraging may unduly bias the results, as discussed by Nemitz et al. [2002] as we shall see the trend is remarkably consistent as the surface type changes.

\section{Mean Deposition Velocity of Small Aerosol as a Function of Surface Roughness}

[12] Values of $v_{d s}$ for each data set were averaged over the smallest measured aerosol size range, $0.1-0.2 \mu \mathrm{m}$ in diameter (the sedimentation velocity, $v_{g}$, was assumed to be negligible for these small particles). The results are 
Table 2. Measured $v_{d s}$ for Small Aerosol $\left(0.1<d_{p}<0.2 \mu \mathrm{m}\right.$ diameter) for Five Different Surface Types

\begin{tabular}{|c|c|c|c|c|}
\hline Surface Type & Mean $v_{d s}, \mathrm{~mm} \mathrm{~s}^{-1}$ & $\sigma_{v d s}, \mathrm{~mm} \mathrm{~s}^{-1}$ & $z_{o}, \mathrm{~m}$ & $H, \mathrm{~m}$ \\
\hline Heathland & 0.71 & 0.07 & 0.01 & 0.06 \\
\hline \multicolumn{5}{|l|}{ Grassland } \\
\hline Short & 0.87 & 0.09 & 0.022 & $0.07-0.14(0.1)^{\mathrm{a}}$ \\
\hline Long & 1.13 & 0.10 & 0.063 & $0.65-1.0(0.75)^{\mathrm{a}}$ \\
\hline Arable crop & 1.38 & 0.41 & 0.12 & 1.2 \\
\hline Forest & 2.08 & 0.52 & 2.5 & $18-20$ \\
\hline
\end{tabular}

${ }^{a}$ Values in parentheses indicate mean height over growth period for which the measurements were made. The value $\sigma$ is the standard deviation for the data set.

presented in Table 2, together with the associated standard deviations for each of the entire data sets. This particular size range corresponds to aerosol flux measurements that are subject to the smallest error arising from statistical-sampling limitations of the instrumentation used due to the high concentrations normally found in this size range. The flux measurements should therefore be the most reliable [Fairall, 1984]. It is immediately clear that, as expected, the surface deposition velocity $v_{d s}$ increases as the canopy height and complexity in surface morphology increases.

[13] The data for the grassland experiments were obtained as part of the EU GRAMINAE programme, which is described in detail by Sutton et al. [2001]. Measurements were made initially over a tall, rapidly growing canopy whose height changed during the experiment from 0.65 to $1.0 \pm 0.02 \mathrm{~m}$ with a mean of $0.75 \pm 0.03 \mathrm{~m}$. The grass canopy was subsequently harvested, altering the canopy height to $0.07 \pm 0.02 \mathrm{~m}$. The aerosol deposition velocity was then remeasured over a period that saw the canopy grow from 0.07 to $0.14 \pm 0.03 \mathrm{~m}$. The measurements of $v_{d s}$, as shown in Table 2, for similar friction speed ranges were apparently able to show the subsequent small change in deposition velocity that resulted due to the change in effective collection area for the particles.

[14] The $v_{d s}$ values for the long-grass and arable crop surfaces show a gradual increase over the heathland, and short-grass values, which were $<0.9 \mathrm{~mm} \mathrm{~s}^{-1}$, increased to values of 1.1 and $1.4 \mathrm{~mm} \mathrm{~s}^{-1}$, respectively. As expected, $v_{d s}$ values for the forest surface are the largest at $2.1 \mathrm{~mm} \mathrm{~s}^{-1}$. As will be discussed later, all of these values are actually smaller than predicted by some current models for forest and arable crop deposition in this particular size range but not dramatically so. (Note that Wyers and Veltkamp [1997] determined the mass deposition velocity, $v_{d}$, for $\mathrm{Pb}^{214}$ to the same Douglas fir canopy to be $7.3 \pm 1.0 \mathrm{~mm} \mathrm{~s}^{-1}$, which corresponds to $v_{d s} \approx 7.9 \mathrm{~mm} \mathrm{~s}^{-1}$, comparable to sulphate throughfall derived deposition values and also for particle deposition velocities in the $0.5-$ to $1.0-\mu \mathrm{m}$ size range [Gallagher et al., 1997b]).

[15] In general, we observe a factor of 2 increase in $v_{d s}$ between grassland and forest for this particular aerosol size range, which is reasonable on the basis of current ideas of collection efficiency parameterization for these surface types. The deviation in $v_{d s}$ within this size range is also larger for the taller canopies, although there is likely a greater stability-related effect at work here for these data sets.
[16] Figure 1 shows the variation of $v_{d s}$ with roughness length, $z_{o}$. The error in $z_{o}$ is often not quoted and as such remains the largest uncertainty. Also shown is the range of predicted values for $v_{d s}$ using the parameterization for small particle deposition velocity obtained by Lamaud et al. [1994b] for a pine forest (Pinus Pinaster Aif). This latter parameterization was based on eddy correlation measurements of total particle fluxes using an electrical ionization counter. Aerosol size discrimination was not available; however, the instrument used to determine these measurements was optimized to detect aerosol of $\sim 0.2 \mu \mathrm{m}$ in diameter. The parameterization derived from their study included the influence of atmospheric stability presented using the usual Wyngaard type formulation,

$$
v_{d s} / u_{*}=k_{1}+k_{2}\left(-z_{i} / L\right)^{2 / 3}=k_{1}+k_{2}(-300 z / L)^{2 / 3},
$$

where $z_{i}$ is the inversion height, $z$ is the measurement height, $L$ is the Monin-Obukhov length, and $k_{1}$ and $k_{2}$ are constants, with $k_{1}$ depending on the surface type and $k_{2}=0.0009$. For the forest database, $k_{1}$ was determined to be 0.004 . Similar measurements to a site with bare soil and sparsely interspersed small trees with a presumably lower roughness length yielded a value for $k_{1}=0.002$. For stable conditions, $v_{d s} / u *$ was quoted as tending to $k_{1}$. This particular parameterization therefore separates the stability dependence from the surface morphology dependence via these two independent terms. This may be questionable, as it has been postulated [Peters and Eiden, 1992] that the observed enhancement in laminar boundary transfer velocity from increasing mean convective motions may be linked to canopy morphology. It is this roughness parameter, $k_{1}$, that we wish to investigate in more detail here. Using the range of values of $u *$ obtained in the current databases together with this parameterization gives the result shown in Figure 1, represented by the shaded bar. The results from soil interspersed by trees are not shown here, as they were quoted with a large range of roughness values but are, in fact, still consistent with the trend observed here.

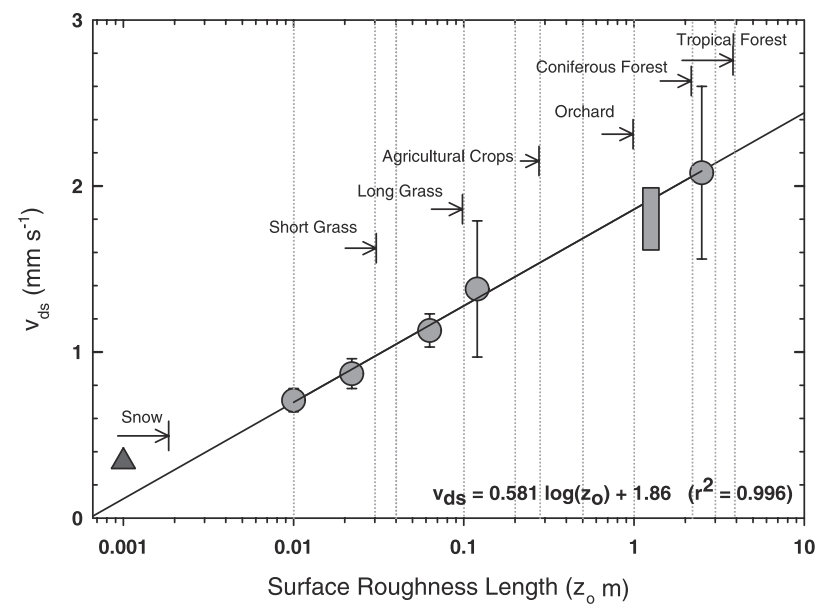

Figure 1. Variation of small particle deposition velocity as a function of roughness length as determined by eddy correlation. Circles, this work; triangle, Duan et al. [1988], snow surface; rectangle, Lamaud et al. [1994c], forest for near-neutral conditions and equivalent friction speed range. 
[17] Concentrating solely on the roughness parameter influence on $v_{d s}$, these data suggest a simple log linear approximation of the following form,

$$
v_{d s}=0.581 \log \left(z_{o}\right)+1.86, \quad r^{2}=0.996
$$

where $v_{d s}$ is in millimeters per second and $z_{o}$ is in meters (there is no consistency in the literature with regards units for $v_{d s}$, both $\mathrm{cm} \mathrm{s}^{-1}$ and $\mathrm{mm} \mathrm{s}^{-1}$ being employed). For applications where the uncertainty in $z_{o}$ is large a similar relationship as a function of canopy height can be obtained from Table 2. This relationship, we therefore argue, has now been partially verified for particles in the size range $0.1-0.2 \mu \mathrm{m}$ diameter and for roughness lengths $>0.005 \mathrm{~m}$. More data are still required to test this relationship in the roughness length range $0.1-1.0 \mathrm{~m}$ and for smooth surfaces such as snow/ice and water. There is some data available for small aerosol deposition rates to snow surfaces; for example, Duan et al. [1988] present deposition velocity data for $0.21 \mu \mathrm{m}$ diameter particles for snow surfaces measured by eddy correlation. The mean for this data (the shaded triangle in Figure 1) is compared with the results obtained in this work. Again the result is very consistent with the trend observed over the vegetated surface data.

[18] We can now extend in a simple manner the equation of Lamaud et al. [1994a] to include the effect of surface roughness through $z_{o}$ finally with

$$
k_{1}=0.001222 \log \left(z_{o}\right)+0.003906 .
$$

The expected variation in $v_{d s} / u_{*}$ for unstable conditions using this function is presented in Figure 2 and remains consistent with the parameterization suggested by Lamaud et al. [1994c] and others [e.g., Gallagher et al., 1997a; Nemitz et al., 2002] in the size range selected here (see Table 1).

[19] Thus a typical variation in regional scale surface roughness length (provided by land-use categories in most regional models) will result in an enhancement in surface deposition for small particles by a factor of between 2 and 5 depending on the atmospheric stability. Of course the additional contribution to the net mass deposition rate will be small in this particle size range but will be important for assessing certain specific species that may be confined to this small size range, e.g., certain heavy metals. The question remains whether a similar-scale effect occurs for larger particles, specifically in the $0.5-1.0 \mu \mathrm{m}$ diameter range, where a significant mass fraction will be located. The extension of the stability-dependent term in (8) to larger particle sizes is important, as it will impact significantly on the dry deposition mass loading. This will be considered in a further paper.

\section{Model Comparison}

[20] It is useful to compare these measurements with current analytical descriptions of the deposition velocity in order to test the physical descriptions governing the main deposition processes for these small particles to complex canopies. Here we adopt the widely used model framework described by Slinn [1982].

\subsection{Slinn Model}

[21] The general framework for parameterizing the deposition velocity, $v_{d}$, for aerosol as a function of their size to

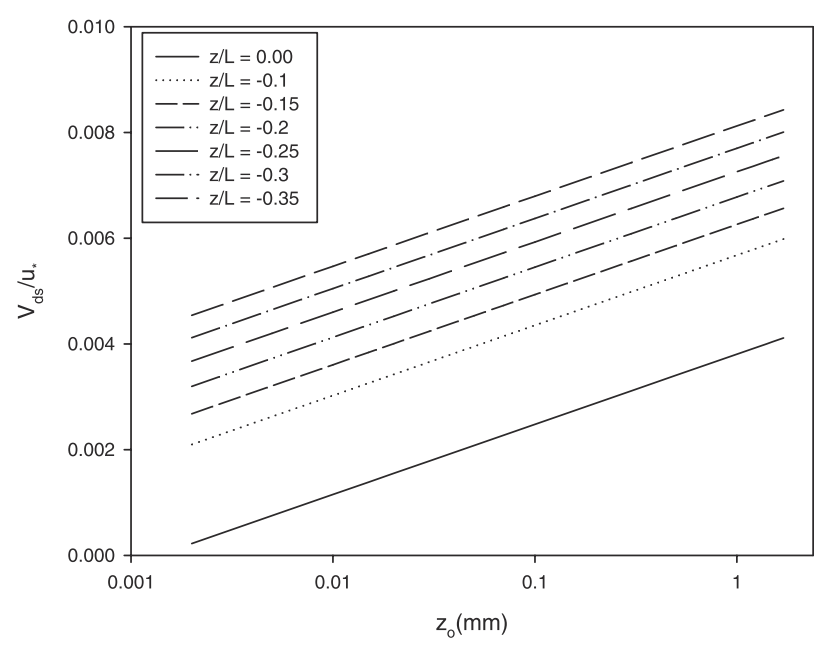

Figure 2. Variation of $v_{d s} / u_{*}$ for small particles as a function of surface of roughness length, $z_{o}$, and surface stability, $z / L$, for unstable.

vegetated surfaces was developed by Slinn [1982]. This model was designed to be used for forest canopies, although many of the underlying parameterizations for the different particle surface interaction mechanisms were based on wind tunnel experiments Chamberlain [1966], and these, in turn, relied on surrogate or short vegetated surfaces, e.g., grass or the heads of wheat stalks. The model attempts to break down the overall deposition process into several stages. These include Brownian diffusion, impaction, interception, gravitational sedimentation, particle rebound, and (in some variants) resuspension. Different processes dominate for different particle size ranges, but typically for the smallest particles, sub $0.1 \mu \mathrm{m}$, it is Brownian diffusion that is most important, whereas impaction and then interception start to dominate as the particles become larger.

\subsection{Aerosol Collection Efficiency}

[22] The critical parameter determining the size dependency for $v_{d}$ is $r_{s}$, the surface resistance. In the Slinn [1982] framework this is parameterized as

$$
r_{s}=\frac{1}{\varepsilon_{0} u_{*} E_{T}},
$$

where the total collection efficiency, $E_{T}$, is parameterized as a series of collection efficiencies for each particle-surface interaction process,

$$
E_{T}=R\left(E_{B}+E_{\mathrm{IM}}+E_{\mathrm{IN}}\right),
$$

where $E_{B}$, the collection efficiency due to Brownian diffusion, depends on the Schmidt number

$$
E_{B}=S c^{-\gamma}=\left(\frac{v}{D}\right)^{-\gamma}
$$

where $S c$ is the ratio of the kinematic viscosity of air, $v$, to the Brownian diffusivity, $D$. The value of $\gamma$ is usually chosen to be between $1 / 2$ and $2 / 3$, with the lower value used for smooth surfaces, e.g., water, and larger values used for 
Table 3. Summary of Aerosol Impaction Parameterizations, $E_{\mathrm{IM}}$, for Different Surfaces ${ }^{\mathrm{a}}$

\begin{tabular}{|c|c|c|c|}
\hline Parameterization & $E_{\mathrm{IM}}$ & Surface Type & Reference \\
\hline 1 & $10^{-\frac{3}{S t}}$ & water/smooth & Slinn and Slinn [1980] \\
\hline 2 & $\frac{S t^{2}}{1+S t^{2}}$ & vegetated & Slinn [1982] \\
\hline 3 & $\left(\frac{S t}{\alpha+S t}\right)^{\beta}$ & spruce forest ${ }^{b}$ & Peters and Eiden [1992] \\
\hline 4 & $\frac{S t^{2}}{400+S t^{2}}$ & smooth & Giorgi [1986] \\
\hline 5 & $\left(\frac{S t}{0.6+S t}\right)^{3.2}$ & vegetated & Giorgi [1986] \\
\hline 6 & $\frac{S t^{3}}{S t^{3}+0.753 S t^{2}+2.796}$ & grassland & Davidson et al. [1982] \\
\hline 7 & $\left(\frac{S t}{3+S t}\right)$ & forest & Wiman and Agren [1985] \\
\hline 8 & $\left(\frac{S t}{\alpha+S t}\right)^{\beta}$ & land use classification ${ }^{\mathrm{c}}$ & \\
\hline
\end{tabular}

rough surfaces, e.g., vegetated surfaces. It is this parameter that is often attributed to different land classes in regional deposition models [e.g., Zhang et al., 2001].

[23] $E_{\mathrm{IM}}$ is the collection efficiency due to impaction of the particle with the collecting surface. This is probably the most important parameter as far as particles in the crucial $0.1-1.0 \mu \mathrm{m}$ diameter range are concerned and, as one might imagine, is the one that has been subject to greatest discussion. Many different parameterizations for $E_{\mathrm{IM}}$ have been suggested; for example, Slinn and Slinn [1980] and Slinn [1982] has suggested two different parameterizations, one for smooth surfaces [Slinn and Slinn, 1980] and one for vegetated surfaces [Slinn, 1982], and this approach has been widely adopted. The crucial parameter defining $E_{\mathrm{IM}}$ is the Stokes number, $S t$, which again has essentially two different parameterizations, one for smooth surfaces [Slinn and Slinn, 1980] and the other for vegetated surfaces [Giorgi, 1986],

$$
\begin{aligned}
& S t(\text { vegetated surface })=\frac{v_{g} u_{*}}{g A} \\
& S t(\text { water/snow surface })=\frac{v_{g} u_{*}^{2}}{v},
\end{aligned}
$$

where $A$ is the characteristic radius for the large collector "rods" that make up the surface. However, the parameterizations suggested for vegetated surfaces are somewhat uncertain due to the lack of quality field data with which to compare.

[24] Table 3, adapted from Ruijgrok et al. [1994], contains most of the current model parameterizations suggested to date, including the enhanced collection efficiency parameterization for forest canopies suggested by Wiman and Agren [1985]. In the subsequent model experiments described below, RWS will refer to the Ruijgrok-WimanSlinn model, which was developed solely for forest surfaces (using parameterization 7 in Table 4) after the observed underestimate in deposition velocity predicted by the original Slinn formulation compared to $v_{d s}$ values derived from throughfall [Ruijgrok et al., 1997]. Thus the only important difference between the RWS and Slinn models is due to the different impaction efficiency parameterization that leads to greater deposition velocities for particles in the crucial accumulation mode size range.

[25] $E_{\mathrm{IN}}$ is the interception collection efficiency based on the relative dimensions of the particle to the collector diameter. This parameter becomes important for larger particles, typically $>0.5-1.0 \mu \mathrm{m}$ diameter. Again a variety of different parameterizations for $E_{\mathrm{IN}}$ exist, and again there is little in the way of field measurements with which to test these parameterizations. The usual approach is to adopt a parameterization based on the relative fractions of large to small collectors that comprise the overall vegetated surface. For simplicity the form adopted by Slinn [1982] is often used.

$$
E_{\mathrm{IN}}=1 / 2\left(\frac{d_{p}}{A}\right)^{2}
$$

Zhang et al. [2001], for example, adopt different values for $A$ in the Canadian Aerosol Model (CAM) for different landuse categories and also vary this parameter with growing season. $R$ is a rebound correction factor to account for the fact that large particles, $>5 \mu \mathrm{m}$ in diameter, are often observed to rebound after hitting a surface and may not be retained as efficiently on average. Slinn [1982] suggests the following form for this parameter, although admitting that it is somewhat arbitrary.

$$
R=e^{-S t^{1 / 2}}
$$

The magnitude of the deposition velocities measured over forests and arable crop shown in Figure 1 for the smaller particle size range summarized in Table 2 is comparable to more recent model predictions [e.g., Ruijgrok et al., 1997; Zhang et al., 2001].

\section{Model Results}

[26] Table 4 summarizes the input parameters common to the Slinn [1982] model framework, where $A_{1}$ and $A_{2}$ are now the dimensions of the smallest and largest collector 
Table 4. Summary of Input Parameters Common to the Slinn [1982] Model Framework

\begin{tabular}{|c|c|c|c|c|c|}
\hline Surface & $\begin{array}{l}\text { Heathland, } \\
\text { Ericaceae } \\
\text { Calluna } \\
\text { Vulgaris }\end{array}$ & $\begin{array}{c}\text { Short Grass, } \\
\text { Graminae } \\
\text { Poaceae }\end{array}$ & $\begin{array}{c}\text { Long Grass, } \\
\text { Graminae } \\
\text { Poaceae }\end{array}$ & $\begin{array}{l}\text { Arable, } \\
\text { Graminae } \\
\text { Poaceae } \\
\text { Triticum } \\
\text { Aestivum } \\
\end{array}$ & $\begin{array}{c}\text { Forest, } \\
\text { Pinaceae } \\
\text { Pseudotsug a } \\
\text { Menziesii }\end{array}$ \\
\hline$H$ & 0.06 & 0.14 & $0.60-0.75$ & 1.2 & $18-20$ \\
\hline$z_{o}$ & 0.01 & 0.022 & 0.063 & 0.12 & 2.5 \\
\hline Slinn parameter ${ }^{a}$ & $b=2$ & $c=0.1$ & $A_{1}=0.5 \mu \mathrm{m}$ & $A_{2}=10 \mu \mathrm{m}$ & $F=1 \%$ \\
\hline \multicolumn{6}{|l|}{ Model results } \\
\hline$v_{d s}^{\mathrm{b}}$ & 1.22 & 1.4 & 2.37 & 1.89 & 3.17 \\
\hline$v_{d s}^{\mathrm{c}}$ & 0.08 & 0.09 & 0.168 & 0.129 & 0.239 \\
\hline$v_{d s}^{\mathrm{d}}$ & 0.71 & 0.87 & 1.13 & 1.38 & 2.08 \\
\hline
\end{tabular}

comprising the surface, $F$ is the percentage of particles collected due to the small collector, and $b$ and $c$ are constant factors. The factors $a$ and $b$ are generally poorly defined. The greatest sensitivity in the Slinn framework is, surprisingly, the relationship between the roughness length and the calculated ratio of the wind speed at the canopy height to that at the measurement reference height [Ruijgrok et al., 1994]. It is this parameter that effectively allows the dependence on canopy surface roughness length to enter into the collection efficiency terms and hence control the deposition velocity. The results for the various experiments are shown in Figure 3, where both the Slinn model results and the RWS scheme results described in section 5 are shown. Obviously, extension of the latter to different roughness lengths appears to underestimate the deposition velocity, which should not be not surprising, whereas the RWS scheme appears to overestimate $v_{d s}$ when extended to

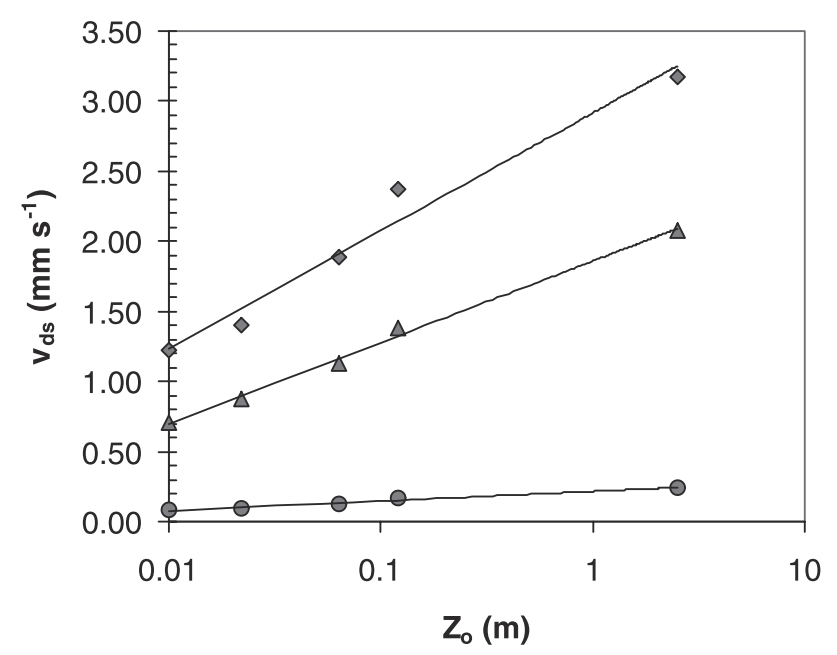

Figure 3. Typical comparison of the Ruijgrok-WimanSlinn (RWS) model schemes and the Slinn [1982] model prediction of $v_{d s}$ for particles in the range of $0.1-0.2 \mu \mathrm{m}$ for different roughness lengths corresponding to each of the experimental surfaces described in Table 2. Diamonds denote the RWS model, triangles denote measurements, and circles denote the Slinn model. (Model $z_{o}$ inferred from canopy dimensions.) simpler surfaces, again as might be expected. The observations lie between the two schemes discussed, indicating a transition from one collection parameterization scheme to the other.

[27] On the basis of these results one could approach a new formulation for the impaction efficiency for these small particles in terms of total collection efficiency (assuming other efficiencies are small in this size range) and could eventually include factors such as leaf area index based on the morphology of the different surfaces; however, this would be premature at this stage, as such an exercise should really incorporate the full particle size dependency. Unfortunately, this requires a more extensive experimental database than currently exists. The size dependency of $v_{d s}$ and a more detailed collection efficiency parameterization as a function of surface type will be discussed in a later paper. For now, either the approach by Zhang et al. [2001] using a collection efficiency depending on land-use classification or (11) and (13) should suffice for small particles. It should be a simple matter to convert (11) and (13) to relevant land classification type for model use. The challenge remains, experimentally, to reliably extend this parameterization to the crucial $0.5-1.0 \mu \mathrm{m}$ diameter size range. These various parameterizations will be discussed with respect to size-segregated deposition measurements in a subsequent paper.

\section{Conclusions}

[28] The results for small $(0.1-0.2 \mu \mathrm{m})$ aerosol particle deposition velocity measured to a number of surfaces have been combined with previously published data. The influence of surface roughness on the surface deposition velocity has been examined and has shown to change in a consistent manner for the various surfaces with the expected increasing trend in $v_{d s}$ with $z_{o}$. A simple parameterization for $v_{d s}$ in terms of $z_{o}$ was obtained as $v_{d s}=0.617 \log \left(z_{o}\right)+1.77$. This was used to extend the results of Lamaud et al. [1994c] for the normalized surface deposition velocity, $v_{d s} / u_{*}=k_{1}+k_{2}$ $(-300 z / L)^{2 / 3}$, with the surface parameter $k_{1}$ now including the roughness length as $k_{1}=0.001222 * \log \left(z_{o}\right)+0.00396$. This result could be usefully adopted in regional-scale dry deposition models for this specific particle size range with- 
out recourse to more sophisticated size-dependent deposition models whose accuracy is still very uncertain due to lack of good measurements capable of resolving collection impaction efficiency.

[29] Comparison between the observations, the original Slinn [1982] model prediction and modified schemes proposed for forests (RWS), shows the former to under predict $v_{d s}$ for all surfaces and the latter to over predict $v_{d s}$, suggesting a collection efficiency dependency lying between those currently implemented. More detailed measurements are needed for surface types with different morphology, particularly in the roughness range $0.1-1.0 \mathrm{~m}$ in order to improve this type of parameterization. Extension of the parameterization to $0.5-1.0 \mu \mathrm{m}$ particles will be considered in further work together with improved size-segregated parameterization of collection efficiency for vegetated surfaces.

[30] Acknowledgments. Various aspects of this work were supported in one form or another by the NERC Environmental Diagnostics Programme, grant GST02238, the EU GRAMINAE Programme (ENV4-CT980722), and the UK NERC URGENT SASUA Programme, grant GST 04/ 2244. R. J. Dorsey was also in receipt of a NERC studentship. We would also like to thank L. Zhang for useful discussions concerning aerosol deposition modeling; the staff at $\mathrm{CEH}$ for their support at the Auchencorth heathland experimental site, the staff led by Ulrich Dämmgen at the Institute for Agroecology at the German Federal Agricultural Research Centre (FAL), Braunschweig, Germany, for their assistance during the GRAMINAE grassland experiment, Mike Flynn and Peter Kelly at UMIST for their assistance with field work and technical support, and Colin Mill and Martin Hill, who designed the hardware and wrote the original software for the aerosol eddy correlation systems used throughout.

\section{References}

Belot, Y., and D. Gauthier, Transport of micronic particles from atmosphere to foliar surfaces, in Heat and Mass Transfer in the Biosphere, Part 1, edited by D. A. de Vries and N. H. Afgan, pp. 582-591, John Wiley, New York, 1976.

Beswick, K. M., M. W. Gallagher, P. Hummelshøj, K. Pilegard, N. O Jensen, and J. Duyzer, Aerosol exchange to Speulder Forest, in Transport and Transformation of Pollutants in the Troposphere: Proceedings of the Eurotrac Symposium '94, edited by P. M. Borrell et al., pp. 683-688, SBP Acad. Publ., The Hague, Netherlands, 1994.

Buzorius, G., Ü. Rannik, J. Mäkelä, T. Vesala, and M. Kulmala, Vertical aerosol fluxes measured by the eddy covariance technique using a condensational particle counter, J. Aerosol Sci., 29, 157-171, 1998.

Buzorius, G., Ü. Rannik, J. Mäkelä, P. M. Keronen, T. Vesala, and M. Kulmala, Vertical aerosol fluxes measured by the eddy correlation method and deposition of nucleation mode particles above a Scots pine forest in southern Finland, J. Geophys. Res., 105, 19,905-19,916, 2000

Chamberlain, A. C., Transport of gases to and from grass and grass-like surfaces, Proc. R. Soc. London, Ser. A, 148, 236-265, 1966.

Davidson, C. I., J. M. Miller, and M. A. Pleskow, The influence of surface structure on predicted particle dry deposition to natural grass canopies, Water Air Soil Pollut., 42, 25-43, 1982.

Dorsey, J. R., E. Nemitz, M. W. Gallagher, D. Fowler, P. I. Williams, K. N. Bower, and K. M. Beswick, Direct measurements and parameterisation of aerosol flux, concentration and emission velocity above a city, Atmos Environ., 36, 791-800, 2002

Duan, B., C. W. Fairall, and D. W. Thomson, Eddy correlation measurements of the dry deposition of particles in wintertime, J. Appl. Meteorol., 27, 642-652, 1988

Duyzer, J. H., and F. C. Bosveld, Measurements of the dry deposition of fluxes of $\mathrm{O}_{3}, \mathrm{NO}_{x}, \mathrm{SO}_{2}$, and particles over grass/heathland vegetation and the influence of surface inhomogeneity, Rep. MT-TNO R 88/111, TNO, Inst. of Environ. Sci., Delft, Netherlands, 1988.

Duyzer, J., H. Westrate, K. Beswick, and M. W. Gallagher, Measurements of the dry deposition flux of sulphate and nitrate aerosols to the Speulderbos using micrometeorological methods, in Dutch Priority Programme on Acidification, Rep. TNO-MW-R 94/255, TNO Inst. of Environ. Sci., Delft, Netherlands, 1994.
Everett, R. G., B. B. Hicks, W. W. Berg, and J. W. Winchester, An analysis of particulate sulphur and lead gradient data collected at Argonne National Laboratory, Atmos. Environ., 13, 931-934, 1979.

Fairall, C. W., Interpretation of eddy correlation measurements of particulate deposition and aerosol flux, Atmos. Environ., 18, 1329-1337, 1984. Flechard, C. R., and D. Fowler, Atmospheric ammonia at a moorland site, II, Long-term surface/atmosphere micrometeorological flux measurements, Q. J. R. Meteorol. Soc., 124, 759-791, 1998.

Fontan, J., A. Lopez, E. Lamaud, and A. Druilhet, Vertical flux measurements of the sub-micronic aerosol particles and parameterization of the dry deposition velocity, in Biosphere-Atmosphere Exchange of Pollutants and Trace Substances, vol. 4, Experimental and Theoretical Studies of Biogenic Emissions and of Pollutant Deposition, edited by S. Slanina, pp. 381-390, Springer-Verlag, New York, 1997.

Gallagher, M. W., K. M. Beswick, J. Duyzer, H. Westrate, T. W. Choularton, and P. Hummelshoj, Atmospheric particles and their interactions with natural surfaces, in Biosphere-Atmosphere Exchange of Pollutants and Trace Substances, vol. 4, Experimental and Theoretical Studies of Biogenic Emissions and of Pollutant Deposition, edited by S. Slanina, pp. 45-93, Springer-Verlag, New York, 1997a.

Gallagher, M. W., K. M. Beswick, J. Duyzer, H. Westrate, T. W. Choularton, and P. Hummelshoj, Measurements of aerosol fluxes to Speulder forest using a micrometeorological technique, Atmos. Environ., 31, 359-373, $1997 \mathrm{~b}$

Giorgi, F., A particle dry-deposition paramaterization scheme for use in tracer transport models, J. Geophys. Res., 91, 9794-9806, 1986.

Hicks, B. B. (Ed.), Deposition Both Wet and Dry, Acid Precip. Ser., vol. 4, Butterworth-Heinemann, Woburn, Mass., 1984.

Hicks, B. B., D. D. Baldocchi, A. J. Meyers, R. P. Hosker, and D. R. Matt, A preliminary multiple resistance routine for deriving dry deposition velocities from measured quantities, Water Air Soil Pollut., 36, $311-$ 330, 1987

Hummelshoj, P., Dry Deposition of Particles and Gases, Ph.D. thesis, Ris $\varnothing$ Natl. Lab., Denmark, Oct. 1992.

Joutsenoja, T., Measurements of aerosol deposition to a cereal crop, in Measurements and Modelling of Gases and Aerosols to Complex Terrain, NERC Rep. GR3/7259, edited by T. W. Choularton et al., Nat. Environ. Res. Counc., UK, 1992.

Katen, P. C., and J. M. Hubbe, Size resolved measurements by eddy correlation of the dry deposition velocity of atmospheric aerosols, in Precipitation Scavenging, Dry Deposition and Resuspension, edited by H. R. Pruppacher, R. G. Semonin, and W. G. Slinn, pp. 953-961, Elsevier Sci., New York, 1983.

Lamaud, E., Y. Brunet, A. Labatut, A. Lopez, J. Fontan, and A. Druilhet, The Landes Experiment: Biosphere-atmosphere exchanges of ozone and aerosol particles above a pine forest, J. Geophys. Res., 99, 16,51116,521, 1994a.

Lamaud, E., A. Labatut, J. Fontan, A. Lopez, A. Druilhet, and Y. Brunet, Biosphere atmosphere exchanges: Ozone and aerosol dry deposition velocities over a pine forest, non $\mathrm{CO}_{2}$ greenhouse gases, why and how to control, Environ. Monit. Assess., 31, 175-181, 1994b.

Lamaud, E., J. Fontan, A. Lopez, and A. Druilhet, Parameterization of the dry deposition velocity of submicron aerosol particles, Air Pollution II, vol. 2, Pollution Control and Monitoring, edited by J. M. Baldasano et al., pp. 433-440, Comput. Mech., Bellerica, Mass., 1994c.

Nemitz, E., M. W. Gallagher, J. H. Duyzer, and D. Fowler, Micrometerological measurements of particle deposition velocities to moorland vegetation, Q. J. R. Meteorol. Soc., in press, 2002.

Nicholson, K. W., The dry deposition of small particles: A review of experimental measurements, Atmos. Environ., 22, 2653-2666, 1988.

Paulson, C. A., The mathematical representation of wind speed and temperature profiles in the unstable atmospheric surface layer, J. Appl. Meteorol., 9, 857-861, 1970.

Peters, K., and R. Eiden, Modelling the dry deposition velocity of aerosol particles to a spruce forest, Atmos. Environ. Part A, 26, 2555-2564, 1992. Pruppacher, H. R., and J. D. Klett, Microphysics of Clouds and Precipitation, D. Reidel, Norwell, Mass., 1980.

Ruijgrok, W., H. Tieben, and P. Eisinga, Dry deposition of acidifying and alkaline particles to Douglas Fir-A comparison of measurements and model results, KEMA Dutch Priority Programme on Acidification Rep. 20159-KES/MLU 94-3216 \# 83397.KC.17-94P02, KEMA, Arnhem, Netherlands, 1994.

Ruijgrok, W., C. I. Davidson, and K. W. Nicholson, Dry deposition of particles-Implications and recommendations for mapping of deposition over Europe, Tellus, Ser. B, 47, 587-601, 1995.

Ruijgrok, W., H. Tieben, and P. Eisinga, The dry deposition of particles to a forest canopy: A comparison of model and experimental results, Atmos. Environ., 31, 399-415, 1997.

Sievering, H., Profile measurements of particle dry deposition velocity at an air-land interface, Atmos. Environ., 16, 301-306, 1982. 
Sievering, H., Eddy flux and profile measurements of small particle dry-deposition velocity at the Boulder Atmospheric Observatory, in Precipitation Scavenging, Dry Deposition and Resuspension, edited by H. R. Pruppacher, R. G. Semonin, and W. G. Slinn, pp. 963-977, Elsevier Sci., New York, 1983

Sievering, H., Small particle dry deposition under high wind speed conditions: Eddy flux measurements at the Boulder Atmospheric Observatory, Atmos. Environ., 21, 2179-2185, 1987.

Sievering, H., Small-particle dry deposition measurements: A comparison of gradient and eddy-flux techniques over agricultural fields, paper presented at 61st Annual Meeting, Air Pollut. Control Agency, Dallas, Tex., 19-24 June, 1988.

Sievering, H., The dry deposition of small particles - A review of experimental measurement, discussion, Atmos. Environ., 23, 2863-2864, 1989.

Slinn, S. A., and W. G. N. Slinn, Predictions for particle deposition on natural waters, Atmos. Environ., 14, 1013-1016, 1980.

Slinn, W. G. N., Predictions for particle deposition to vegetative canopies, Atmos. Environ., 16, 1785-1794, 1982.

Sutton, M. A., et al., Biosphere-atmosphere interactions of ammonia with grasslands: Experimental strategy and results from a new European initiative, Plant Soil, 228(1), 131-145, 2001.

Wesely, M. L., B. B. Hicks, W. P. Dannevik, S. Frisella, and R. B. Husar, An eddy correlation measurement of particulate deposition from the atmosphere, Atmos. Environ., 11, 561-563, 1977.

Wesely, M. L., D. R. Cook, and R. L. Hart, Fluxes of gases and particles above a deciduous forest in wintertime, Boundary Layer Meteorol., 27, 237-255, 1983a.

Wesely, M. L., D. R. Cook, R. L. Hart, B. B. Hicks, G. L. Durham, R. E. Speer, D. H. Stedman, and R. J. Tropp, Eddy correlation measurements of dry deposition of particulate sulphur and submicron particles, in Precipitation Scavenging, Dry Deposition and Resuspension, edited by H. R. Pruppacher, R. G. Semonin, and W. G. N. Slinn, p. 943, Elsevier Sci., New York, 1983b.
Wesely, M. L., D. R. Cook, R. L. Hart, and R. E. Speer, Measurements and parameterization of particulate sulfur dry deposition over grass, J. Geophys. Res., 90, 2131-2143, 1985

Wiman, B. L. B., and G. I. Agren, Aerosol depletion and deposition in forests-A model analysis, Atmos. Environ., 19, 335-362, 1985.

Wyers, G. P., Overview of ammonia and aerosols, paper presented at Workshop on Deposition and Biogenic Emission, EUROTRAC-Biatex, Madrid, 16-17 Jan., 1995.

Wyers, G. P., and J. H. Duyzer, Micrometeorological measurement of the dry deposition flux of sulphate and nitrate aerosols to coniferous forest, Atmos. Environ., 31, 333-343, 1997.

Wyers, G. P., and A. C. Veltkamp, Dry deposition of Pb-214 to conifers, Atmos. Environ., 31, 345-350, 1997.

Wyers, G. P., Veltkamp, A. T. Vermeulen, M. Geusebroek, A. Wayers, and J. J. Möls, Deposition of aerosol to coniferous forest., ECN Rep. C-94051, Neth. Energy Res. Found., Petten, 1994.

Zhang, L., S. Gong, J. Padro, and L. Barrie, A size-segregated particle dry deposition scheme for an atmospheric aerosol module, Atmos. Environ., $35,549-560,2001$

R. J. Dorsey, M. Flynn, and M. W. Gallagher, Physics Department, University of Manchester Institute of Science and Technology, Main Building, P.O. Box 88, Manchester M60 1QD, UK. (martin.gallagher@) umist.ac.uk)

J. Duyzer, TNO-MEP, Business Park ETV, Laan van Westernenk, P.O. Box 342, Apeldoom, NL-AH 7300, Netherlands. (j.h.duyzer@mep.tno.nl)

D. Fowler, E. Nemitz, and M. A. Sutton, Centre for Ecology Hydrology, Penicuik, Midlothian EH26 0QY, UK. (dfo@wpo.nerc.ac.uk; en@ceh. ac.uk) 